\title{
Aa. Vv., «Ponts/Ponti, langues, littératures, civilisations des Pays francophones», n. 6, Mariages
}

Simona Rossi

\section{(2) OpenEdition}

1 Journals

\section{Edizione digitale}

URL: http://journals.openedition.org/studifrancesi/9347

DOI: $10.4000 /$ studifrancesi.9347

ISSN: 2421-5856

\section{Editore}

Rosenberg \& Sellier

\section{Edizione cartacea}

Data di pubblicazione: 1 juin 2008

Paginazione: 227

ISSN: 0039-2944

\section{Notizia bibliografica digitale}

Simona Rossi, «Aa. VV., «Ponts/Ponti, langues, littératures, civilisations des Pays francophones», n. 6 , Mariages», Studi Francesi [Online], 154 (LII | I) | 2008, online dal 30 novembre 2015, consultato il 10 janvier 2021. URL: http://journals.openedition.org/studifrancesi/9347 ; DOI: https://doi.org/10.4000/ studifrancesi.9347

Questo documento è stato generato automaticamente il 10 janvier 2021.

\section{(c) (†) $\ominus$}

Studi Francesi è distribuita con Licenza Creative Commons Attribuzione - Non commerciale - Non opere derivate 4.0 Internazionale. 


\title{
Aa. Vv., «Ponts/Ponti, langues, littératures, civilisations des Pays francophones», n. 6, Mariages
}

\author{
Simona Rossi
}

\section{NOTIZIA}

«Ponts/Ponti, langues, littératures, civilisations des Pays francophones», n. 6, 2006, Mariages, pp. 334.

Il tema del matrimonio rappresenta molto bene l'essenza delle culture e delle letterature francofone nel mondo, come simbolo di unione feconda, di dialogo, di collaborazione e scambio tra realtà e tradizioni differenti. Lo stesso Léopold Sédar Senghor, pur non trattando mai il tema del matrimonio nella sua opera, non esita a scegliere il verbo épouser per tradurre un'immagine di fraternità nella sua poesia Méditerranée. Questo numero della rivista «Ponts/Ponti» trae ispirazione proprio dai suoi versi e si propone di offrire un panorama del tema matrimoniale nelle letterature francofone, scegliendo alcuni scrittori rappresentativi delle diverse aree, dal Belgio alle Antille, passando per l'Africa e per il Québec. La prima parte del volume (la seconda è, come in ogni numero, occupata dalle «Notes de lecture»), introdotta da Marco Modenesi, si compone di cinque corposi saggi: Silvio FERRARI, Chez Brel le mot mariage est un faux-semblant (pp. 13-36); Giuliva MILÒ, Le mariage entre merveilleux et réalité dans " $\mathrm{L} a$ colline oubliée" de Mouloud Mammeri (pp. 37-53); Liana NISSIM, "Elle méritait quelques jours de bonheur". Scènes de mariage dans les littératures africaines (pp. 55-73); Anna Paola MOSSETTO, De quelques mariages sur la scène québécoise: la mouvance de l'esprit mythique (pp. 75-93); Marco MODENESI, Ravages de noces. Couples et mariages dans "Histoire de la femme cannibale" de Maryse Condé (pp. 95-107). Seguono testi inediti di Cristina BRANCALION, Parfait JANS et André BROCHU. 
2 Gli autori analizzati permettono di costruire un discorso complessivo che rispecchia bene le diverse forme di rappresentazione del matrimonio nelle letterature di lingua francese. Mouloud Mammeri, ad esempio, nel suo romanzo La colline oubliée fa convergere nel matrimonio dei suoi protagonisti lo sconfinato amore africano per la tradizione, lasciando intravedere un vigoroso scorcio dell'affermarsi della superiorità maschile, che pure non rinnega un rispetto tutto particolare per la figura femminile. Ahmadou Kourouma, dal canto suo, mostra ai lettori i meandri oscuri e misteriosi dei matrimoni combinati, mentre Mariama Bâ, Moussa Konaté e Cheick Aliou Ndao si addentrano nella fitta rete di problematiche riguardanti i cambiamenti sociali ed ideologici subiti da questa istituzione nel delicato passaggio dalle società ancestrali al contesto urbano, tratteggiando in parte anche le caratteristiche della famiglia poligama, simbolo per certi versi della tradizione africana più pura ed autentica.

Il quadro narrativo quebecchese, invece, svela, in un affascinante gioco di luci e d'ombre, i volti contrastanti della realtà matrimoniale, 'luogo' al tempo stesso di alienazione e di rifugio per i personaggi: Marie-Claire Blais, ad esempio, spinge le sue eroine ad abbandonare il grigiore che si annida sotto il tetto coniugale per spingersi oltre i confini familiari, dove risplendono libertà e indipendenza. È dello stesso avviso Anne Hébert, dalla cui penna escono donne soffocate da mariti padroni e psicopatici, donne che desiderano respirare aria pulita, alla ricerca di nuove occasioni, di altri traguardi ed incontri, di altri orizzonti da esplorare. Per la letteratura delle Antille, infine, viene analizzato un testo paradigmatico per la rappresentazione della situazione matrimoniale nell'area caraibica: L'histoire de la femme cannibale di Maryse Condé, la cui giovane protagonista è, come nei romanzi delle scrittrici québecchesi, prigioniera del giogo soffocante del suo velo da sposa.

4 Le oltre duecento pagine delle «Notes de lectures» (accanto alle sezioni dedicate alle diverse aree francofone c'è anche una sezione linguistica) completano questo ricco numero che, come è ormai tradizione della rivista, pur dedicandosi ad una tematica particolare apporta sempre un contributo generale importante agli studi delle letterature di lingua francese. 